\title{
Study on aging parameters and effect of rice wine based on aging device
}

\author{
Hongjun $\mathrm{Ni}^{1}$, Kaixuan Wang ${ }^{1,2}$, Qijun $\mathrm{Shi}^{3}$, Shuaishuai Lv ${ }^{1, *}$, Yonglan Liu ${ }^{3}$, Ruobo Gu ${ }^{3}$, Xingxing Wang ${ }^{1}$ \\ ${ }^{1}$ School of Mechanical Engineering, Nantong University, Nantong 226019, China \\ ${ }^{2}$ Graduate School of Advanced Technology and Science, University of Tokushima, Tokushima 770-8506, Japan \\ ${ }^{3}$ Nantong Vocational College of Science \& Technology, Nantong 226019, China
}

\begin{abstract}
Rice wine is a kind of low alcohol and high nutrition four season drinking wine made from water and glutinous rice. Generally, new rice wine needs to undergo a natural aging process for about 1 year. In order to solve the problems of long natural aging period and poor aging effect of rice wine, a set of rice wine aging device was designed and a comprehensive method was used to age the rice wine. By orthogonal experiments, the optimal aging process parameters were determined, which were temperature $55^{\circ} \mathrm{C}$, aging time 12 days, and hydrogen peroxide addition $4 \mathrm{~mL} / 200 \mathrm{~mL}$. The results show that the content of ethyl acetate and ethyl lactate in rice wine are $0.44 \mathrm{~g} / \mathrm{L}$ and $0.80 \mathrm{~g} / \mathrm{L}$ respectively and the content of total acid and total sugar reaches $6.9 \mathrm{~g} / \mathrm{L}$ and $230.2 \mathrm{~g} / \mathrm{L}$ respectively. Compared with naturally aged rice wine, it is verified that the effect of artificial aging can achieve the effect of natural aging for one year. This experiment provides a new method for the study of artificial aging of rice wine.
\end{abstract}

\section{INTRODUCTION}

Rice wine is brewed from water and glutinous rice by many processes. It is a kind of low alcohol, high nutrition four season drinking wine with a transparent amber color, rich fragrance and mellow taste. However, In the process of brewing, fusel oil will be produced, which will lead to poor taste of wine and greatly affects the drinking experience [1-2]. Therefore, the manufacturer will store the wine for one or three years or even longer, so that the taste of the wine becomes soft and with a long aftertaste [3]. This kind of storage process is called aging (also known as aging or mellowing) to eliminate the spiciness of the wine and increase its mellow feeling.

Aging treatment is a very important process in rice wine making process, which directly affects the quality of wine [4]. The main function of the aging device is to reduce the harmful components and fusel oil, so as to make the oxidation reactions and promote the esterification reaction between alcohol and acid, finally make the wine fragrant, sweet and soft. As a kind of widely used food, rice wine has strict requirements and regulations in hygiene, food safety and other aspects [5]. Therefore, it is very important to study the aging technology and equipment of rice wine.

\section{MATERIALS AND METHODS}

\subsection{Samples preparation}

\subsubsection{Pre-treatment part}

The aging device was composed of pre-treatment part and aging part. Heat preservation and mechanical agitation were integrated to pre-treat the rice wine. As shown in Figure 1, the pre-treatment part includes frame, reaction kettle, transmission device, heating device, motor, and so on. The frame part is composed of the shell and the handle. The shell adopts the thin-walled design of the revolving body, and the handle adopts the hollow thin-walled design. The revolving structure was used in reaction kettle, the wall thickness was $1 \mathrm{~mm}$ and material were stainless steel 304 with food grade.

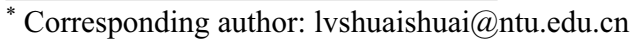




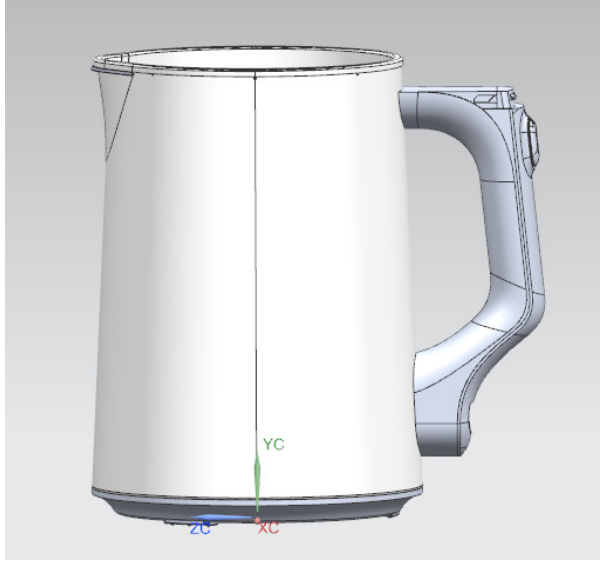

Fig. 1. Structure of pretreatment part

The transmission device was composed of transmission shaft, fan, turbulence net, stirring tool and other auxiliary parts. The transmission shaft and the motor were connected as a whole, and the fan is connected with turbulence network by bolts. In order to heat uniformly, stereo surrounding heating method was used in heating device. The heat transfer carrier was heated by the heating equipment, so as to transfer heat to the water bath layer, finally the wine was heated, which can stir at the same time.

\subsubsection{Aging part}

The aging part was composed of aging kettle and constant temperature water bath with magnetic stirring. The revolving structure was also used in aging kettle, and the wall thickness and material were consistent with the reaction kettle. The constant temperature water bath with magnetic stirring adopts HCJ-4D with double row and four holes, which is easy to operate and stable in performance. And the temperature accuracy can be reached $0.1{ }^{\circ} \mathrm{C}$, which meet the requirements and efficient.

\subsubsection{Construction of aging device}

The overall dimension is $175 \mathrm{~mm} \times 230 \mathrm{~mm} \times 300 \mathrm{~mm}$, where rice wine with $5300 \mathrm{~mL}$ can be aged for $18 \mathrm{~min}$ at a time. The prototype is shown in Figure 2 and Figure 3.

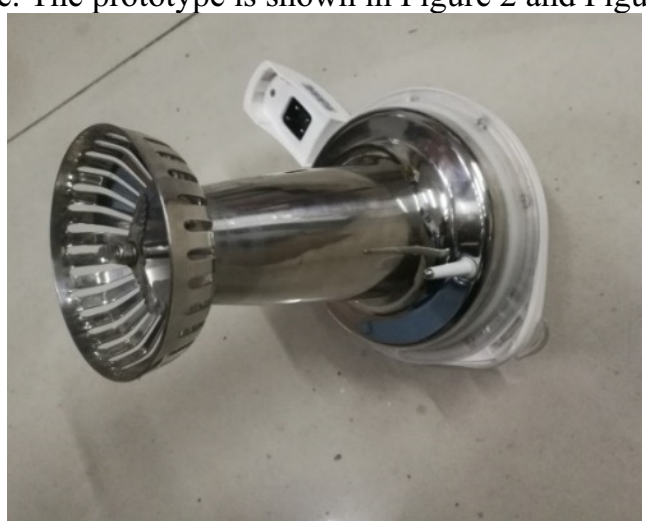

Fig. 2. Prototype of transmission device

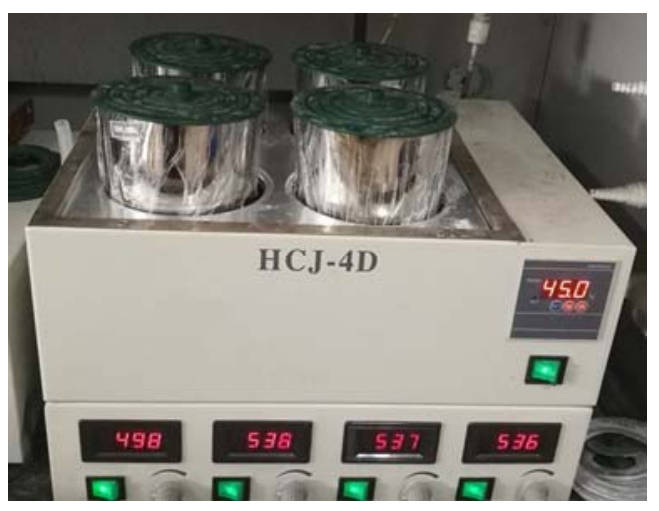

Fig. 3. Prototype of aging device

\subsection{Methods}

\subsubsection{Experiment methods}

Firstly, rice wine is pre-treated. $1000 \mathrm{~mL}$ sample of rice wine was poured into the reaction kettle before the head was installed. Then, the rotating shaft and fan were rotated by the motor at high speed. Therefore, the molecular activation energy was increased by high-speed stirring (mechanical stirring speed is $8000-10000 \mathrm{r} / \mathrm{min}$, time is $15 \mathrm{~min}$ ) and the hydrogen bond between ethanol molecules and water molecules were opened, which accelerated the rate of chemical reaction and promoted oxidation and esterification. Finally, samples were taken after 18 minutes of treatment. The experimental diagram is shown in Figure 4.

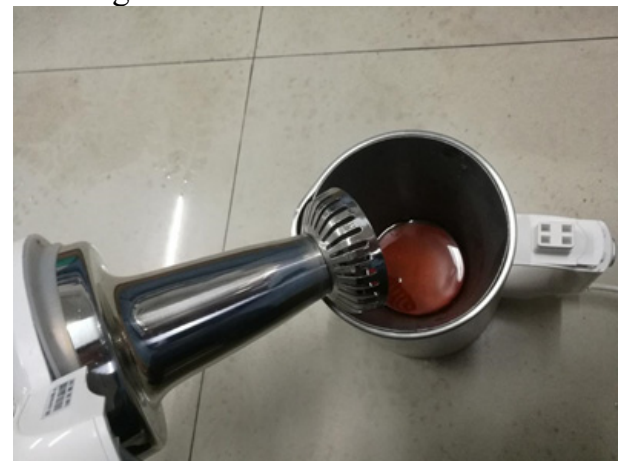

Fig. 4. Pre-treatment process

Then the aging treatment is carried out shown in Figure 5. New sample of rice wine after pre-treatment with a certain amount of oxidant was poured into the reactor kettle, which was sealed with the preservative film and then put into the aging treatment device. Aging treatment holding for 3-12 days, was carried out with the temperature of $40{ }^{\circ} \mathrm{C}-55^{\circ} \mathrm{C}$ and hydrogen peroxide addition was 0-6 $\mathrm{mL}$. 


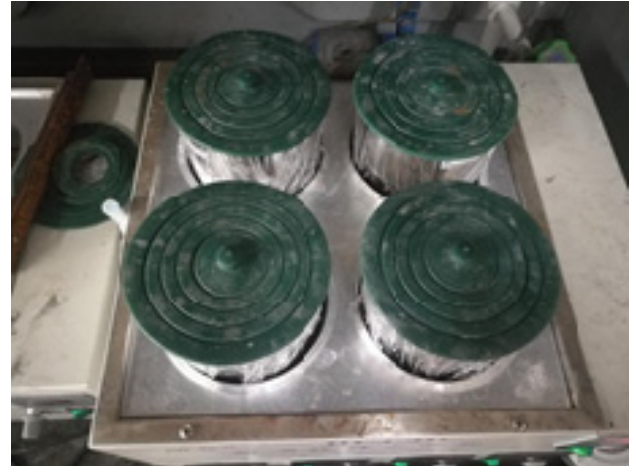

Fig. 5. Aging treatment

\subsubsection{Sensory evaluation methods}

Table 1 shows the evaluation standard of rice wine which is divided into four aspects: color, aroma, taste and flavor. The total score is 100 and was assigned according to the importance of each aspects [6]. A comprehensive grade is obtained by calculating the score and matching it with the grade.

Table 1. Evaluation standards table

\begin{tabular}{|c|c|c|c|c|}
\hline Grade & $\begin{array}{c}\text { Color } \\
(10 \\
\text { points })\end{array}$ & $\begin{array}{c}\text { Aroma } \\
(25 \\
\text { points })\end{array}$ & $\begin{array}{c}\text { Taste } \\
(50 \\
\text { points })\end{array}$ & $\begin{array}{c}\text { Flavor }(15 \\
\text { points })\end{array}$ \\
\hline Excellent & 10 & 25 & $45-50$ & 15 \\
\hline Good & $7-9$ & $20-25$ & $31-44$ & $11-15$ \\
\hline Average & $3-6$ & $7-19$ & $16-30$ & $4-10$ \\
\hline Poor & $1-2$ & $1-6$ & $1-15$ & $1-3$ \\
\hline
\end{tabular}

\subsubsection{Indicators evaluation methods}

The main esters in rice wine are ethyl lactate and ethyl acetate, which are important flavor substances in the wine and make it mellow and fragrant [7]. The content of total ester is an important index reflecting the aging effect of rice wine. The measurement method refers to the Chinese national standard GB/T 27588-2011. First, take $50.0 \mathrm{~mL}$ of sample in a reflux flask and neutralize the free acid in the sample with $25.00 \mathrm{~mL}$ of $0.1 \mathrm{~mol} / \mathrm{L}$ standard sodium hydroxide accurately, then heat the reflux to saponify the esters. The content of total ester through the amount of alkali consumed was calculated by the following equations:

$$
X_{1}=\frac{\left(C \times 25-C_{1} \times V_{1}\right)}{25} \times 1000
$$

where $\mathrm{X}_{1}$ is the content of total ester; $\mathrm{C}$ is concentration of sodium hydroxide; $\mathrm{C}_{1}$ is molar concentration of sulfuric acid; $\mathrm{V}_{1}$ is consumed volume of alkali.

The sugars in rice wine are the hydrolysates of starch, which plays an important role in the flavor [8]. Accounting to the Chinese national standard GB/T 13662-2008, the content of total sugar is determined by Lian Ainong method:

$$
X_{2}=\frac{500 \times m_{1}}{V_{\mathrm{t}} \times V_{s}} \times 1000
$$

where $\mathrm{X}_{2}$ is the content of total sugar; $\mathrm{m}_{1}$ is the content of equivalent sugar; $V_{t}$ is the volume of hydrolysate consumed by titration; $\mathrm{V}_{\mathrm{s}}$ is the volume sample.

Acid is one of the important flavor substances in rice wine. The increase of acid content can improve the ripeness of rice wine [9]. Accounting to the Chinese national standard GB/T 10345-2007, the total acid is determined by potentiometric titration:

$$
X_{3}=\frac{C_{2} \times\left(V_{1}-V_{0}\right) \times 0.09}{V} \times 1000
$$

where $\mathrm{X}_{3}$ is the content of total acid; $\mathrm{C}_{2}$ is the concentration of sodium hydroxide; $\mathrm{V} 0$ is the volume of standard sodium hydroxide consumed in blank by titration.

\section{Results and discussion}

\subsection{Experiment results}

In general, with the increase of temperature, the chemical reaction rate will accelerate obviously. According to the vant Hoff rule, the chemical reaction rate increase by $2-4$ times for every $10{ }^{\circ} \mathrm{C}$ rise of temperature [10]. First, set aging temperature at $40{ }^{\circ} \mathrm{C}$, $50{ }^{\circ} \mathrm{C}, 60{ }^{\circ} \mathrm{C}$, aging time for 3 days, 6 days, 9 days, 12 days respectively. Partial experiment results are shown in the Figure 6.

When the same aging treatment for 3 days under the temperature of $50{ }^{\circ} \mathrm{C}$ and $60{ }^{\circ} \mathrm{C}$, the colour of the wine body is slightly deepened, and it tastes slightly sweet after tasting by professionals, but still spicy when the temperature is $40{ }^{\circ} \mathrm{C}$. As the aging time increases, Figure 6(b) shows that the colour of wine does not change significantly at $40{ }^{\circ} \mathrm{C}$, and the taste still spicy. Although at $60{ }^{\circ} \mathrm{C}$, after aging for 6 days, it can be seen from the Figure 6(f) that the colour of the wine body is obviously deepened, and after tasting by professionals, the sweetness is obvious, but there is caramel smell, and the wine body becomes turbid, which affects the quality of the wine. Maybe it is because when the temperature is over $60{ }^{\circ} \mathrm{C}$, the Maillard reaction will be intensified, and the reaction between glucose and amino acid will result in the loss of nutrition and the products are not easy to digest. Compared with $60^{\circ} \mathrm{C}$, after aging at $50^{\circ} \mathrm{C}$ for 12 days, the colour of the wine becomes darker, the taste is sweeter, and there is no precipitation. To sum up, the best temperature range is $50{ }^{\circ} \mathrm{C}-55^{\circ} \mathrm{C}$.

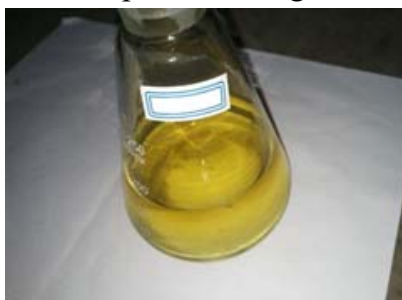

(a)

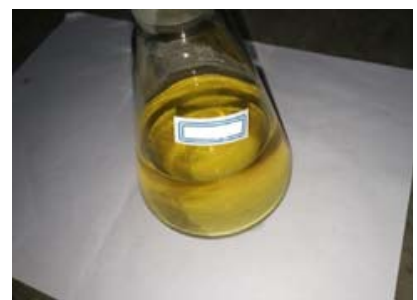

(b) 


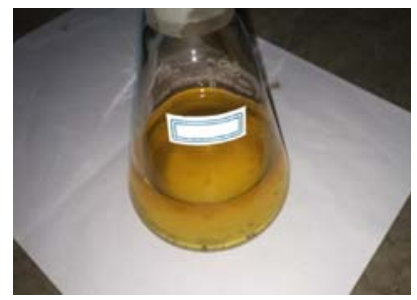

(c)

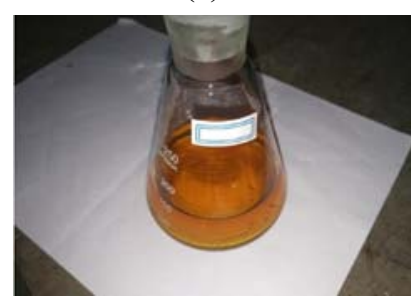

(e)

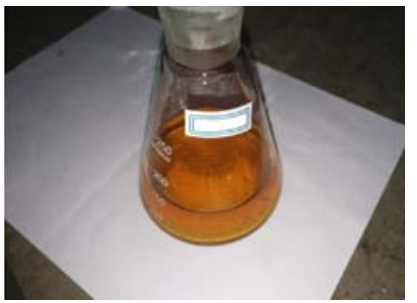

(d)

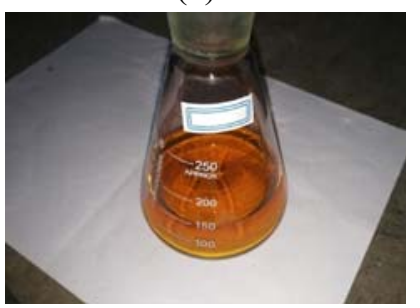

(f)
Fig. 6. Results of single factor experiment: (a) $40{ }^{\circ} \mathrm{C}$ for 3 days; (b) $40{ }^{\circ} \mathrm{C}$ for 12 days; (c) $50{ }^{\circ} \mathrm{C}$ for 3 days; (d) $50{ }^{\circ} \mathrm{C}$ for 12 days; (e) $60^{\circ} \mathrm{C}$ for 3 days; (f) $60^{\circ} \mathrm{C}$ for 6 days.

During the aging process of rice wine, oxidation reaction, esterification reaction and Maillard reaction take place [11]. There are many factors that affect the quality of rice wine. In order to choose the optimum aging process of rice wine, three factors were considered: aging temperature, aging time and hydrogen oxidant addition. L16 $\left(4^{3}\right)$ orthogonal test was carried out with aging temperature $\mathrm{A}$, aging time $\mathrm{B}$ and addition amount of hydrogen peroxide $\mathrm{C}$ as influencing factors. The selected orthogonal test factors and their levels are shown in Table 2.

Table 2. The factors and their levels for L16 $\left(4^{3}\right)$ orthogonal test.

\begin{tabular}{|c|c|c|c|}
\hline \multirow{2}{*}{ Levels } & \multicolumn{3}{|c|}{ Factors } \\
\cline { 2 - 4 } & $\begin{array}{c}\mathrm{A} \\
\text { Aging } \\
\text { temperature }\end{array}$ & $\begin{array}{c}\mathrm{B} \\
\text { Aging } \\
\text { time }\end{array}$ & $\begin{array}{c}\mathrm{C} \\
\text { hydrogen } \\
\text { peroxide }(0.30 \%)\end{array}$ \\
\hline 1 & $40^{\circ} \mathrm{C}$ & 3 days & 0 \\
\hline 2 & $45^{\circ} \mathrm{C}$ & 6 days & $2 \mathrm{~mL} / 200 \mathrm{~mL}$ \\
\hline 3 & $50^{\circ} \mathrm{C}$ & 9 days & $4 \mathrm{~mL} / 200 \mathrm{~mL}$ \\
\hline 4 & $55^{\circ} \mathrm{C}$ & 12 days & $6 \mathrm{~mL} / 200 \mathrm{~mL}$ \\
\hline
\end{tabular}

\subsection{Aging effect analysis}

\subsubsection{Sensory evaluation}

According to the evaluation standard of rice wine, five evaluators conducted sensory evaluation on the colour, aroma, taste and style. The best aging process parameters are used to aging the rice wine, and the sensory evaluation results are shown in table 3 .

Table 3. Sensory results of rice wine by artificial aging

\begin{tabular}{|c|c|c|c|c|}
\hline Grade & $\begin{array}{c}\text { Color (10 } \\
\text { points) }\end{array}$ & $\begin{array}{c}\text { Aroma (25 } \\
\text { points) }\end{array}$ & $\begin{array}{c}\text { Taste (50 } \\
\text { points) }\end{array}$ & $\begin{array}{c}\text { Flavor (15 } \\
\text { points) }\end{array}$ \\
\hline Good & 9 & 23.5 & 44 & 14 \\
\hline
\end{tabular}

\subsubsection{Physical and chemical indicators}

(1) Change of total ester

The ethyl acetate and ethyl lactate in the new rice wine are $0.06 \mathrm{~g} / \mathrm{L}$ and $0.12 \mathrm{~g} / \mathrm{L}$ respectively. After artificial aging treatment, the contents were $0.44 \mathrm{~g} / \mathrm{L}$ and $0.80 \mathrm{~g} / \mathrm{L}$ respectively which are close to one-year aging of $0.48 \mathrm{~g} / \mathrm{L}$ and $0.85 \mathrm{~g} / \mathrm{L}$, as shown in Figure 7 and Figure 8 . With the increase of ethyl acetate and ethyl lactate content, the flavor of rice wine was enhanced, and made rice wine more mellow and full-bodied [12]. In the aging process, ethanol was gradually oxidized to acetaldehyde that was finally oxidized to acetic acid, and then ethyl acetate was produced by esterification of ethanol and acetic acid. Lactic acid was produced by lactobacillus during fermentation, and then ethyl lactate was produced by esterification of lactic acid and ethanol which increased the content of esters in rice wine [13].

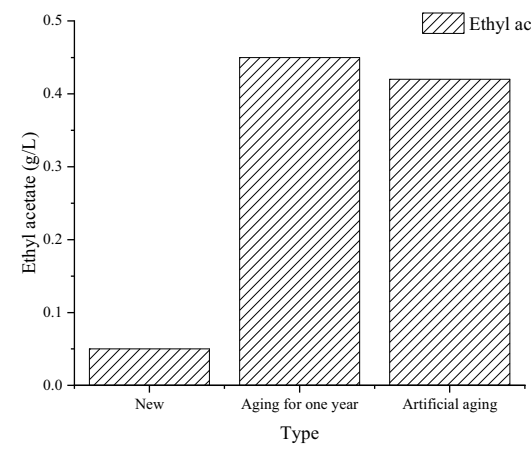

Fig. 7. Changes of ethyl acetate

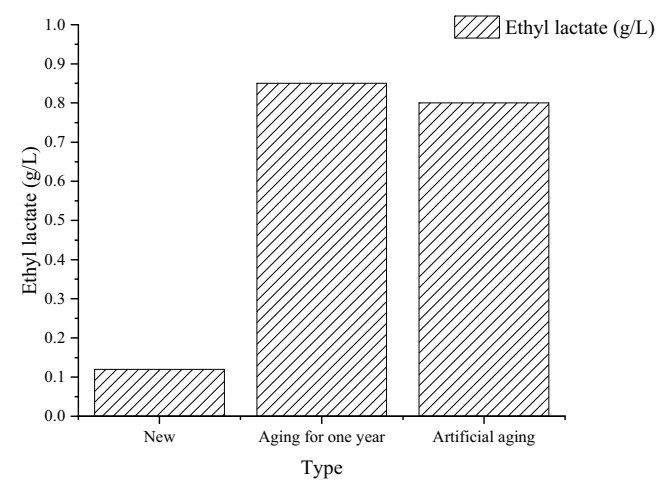

Fig. 8. Changes of ethyl lactate

(2) Change of total acid

The content of total acid was $3.5 \mathrm{~g} / \mathrm{L}$ in new wine and reached $6.9 \mathrm{~g} / \mathrm{L}$ after artificial aging treatment, which was significantly increased. The effect of artificial aging is obvious because the content of total acid in natural aging is reduced, as shown in Figure 9. The main reason for the increase of total acid was that hydrogen peroxide used as oxidant for oxidation reaction was added during artificial aging to promote the oxidation of ethanol to acetaldehyde, and further oxidation to acetic acid [14]. On the other hand, the hydrolysis of esters also produced acids, so as to increase the total acid content and improve the taste of rice wine. 


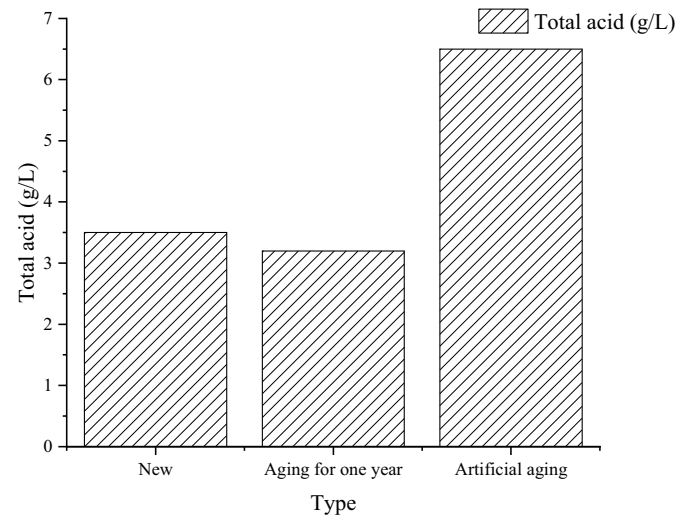

Fig. 9. Change of total acid

(3) Change of total sugar

Figure 10 shows the change of total sugar before and after aging. The total sugar content of the new wine is $154 \mathrm{~g} / \mathrm{L}$. After aging treatment using designed aging device, the total sugar content is $230.2 \mathrm{~g} / \mathrm{L}$. Compared with the new rice wine, the total sugar content is significantly increased, which is similar to that of rice wine with natural aging for 1 years. The main reason for the increase of total sugar content in rice wine is that starch decomposes into polysaccharide and a small amount of glucose under the action of amylase. In the aging process, with the increase of temperature, polysaccharide decomposes glucose gradually. In addition, Maillard reaction consumes a small amount of glucose, so that the content of total sugar increases significantly and the taste of rice wine is improved.

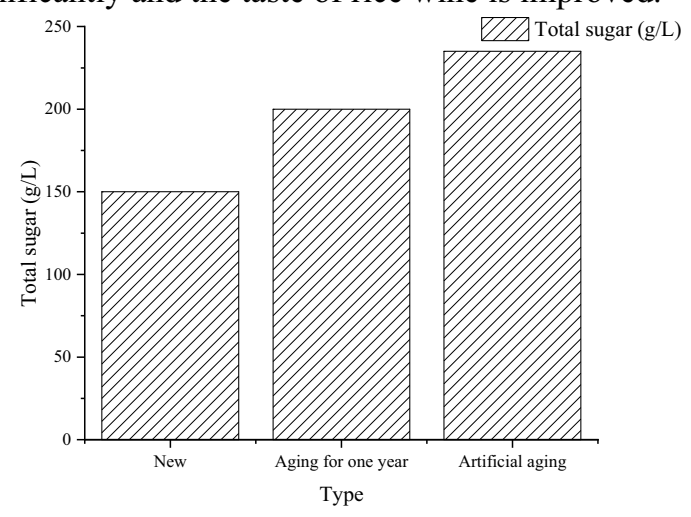

Fig. 10. Change of total sugar

\section{Conclusions}

According to the aging environment and process of rice wine, the aging device for rice wine was developed. The aging device includes pretreatment part and aging part and the new rice wine was aged by this device. The effects of various factors on the aging treatment of rice wine were studied by selecting the temperature, aging time and the hydrogen peroxide addition as the main factors. Total acid, total ester and total sugar were selected as the physical and chemical indexes of rice wine. The comprehensive evaluation of rice wine was carried out by comparing the indexes and combining the sensory scores. The results showed that the content of ethyl acetate and ethyl lactate in rice wine were $0.44 \mathrm{~g} / \mathrm{L}$ and $0.80 \mathrm{~g} / \mathrm{L}$ respectively and the content of total acid and total sugar reached $6.9 \mathrm{~g} / \mathrm{L}$ and $230.2 \mathrm{~g} / \mathrm{L}$ respectively. The aging effect was equivalent to that of natural aging for about one year. The designed aging device had obvious effect of accelerating the aging of rice wine and provided a new method for the study of artificial aging of rice wine.

\section{References}

1. M.L. Xu, S.M. Zhu; Y. Yu, Scientific Reports, 7, 6541 (2017)

2. M.L. Xu, Y. Yu, H. S. Ramaswamy, Scientific Reports, 7, 39671 (2017)

3. A. Tzachristas, K. Pasvanka, M. Liouni, Appl. Sci, 10, 3444 (2020)

4. H. Hu, S. Dai, A. Wen, Animals, 9, 65 (2019)

5. M. Diana, J. Quílez, M. Rafecas, Journal of Functional Foods, 10, 407-420 (2014)

6. J. Chen, D. Chen, X. Zhang, Journal of Chromatography A, 1568, 22-28 (2018)

7. A.C. Marin, F. Chinnici, Appl. Sci., 10, 6877 (2020)

8. Q.A. Zhang, Y. Shen, X.H. Fan, CyTA - Journal of Food, 14, 55-64 (2015)

9. S.M. Zhu, M.L. Xu, H. S. Ramaswamy, Scientific Reports, 6, 30273 (2016)

10. R.M. Aadil, X.A. Zeng, Z. Han, Food Chemistry, 141, 3201-3206 (2013)

11. M. Liu, K. Yang, Y. Qi, Journal of the Institute of Brewing, 124, 269-275 (2018)

12. D. Wang, L. Chen, F. Yang, Journal of the Institute of Brewing, 125, 214-221 (2019)

13. R. Gawel, A. Schulkin, P.A. Smith, Australian Journal of 22Grape and Wine Research, 26, 172-179 (2020)

14. R. Bhat, N.S. Kamaruddin, M.Z. Liong, Ultrasonics Sonochemistry, 18, 1295-1300 (2011) 